\title{
Design of Compact Wideband Circularly Polarized Conical Helix
}

\author{
J.N. Mei, D.W. Ding \\ Department of Electronic Engineering and Information \\ Science, University of Science and Technology of China \\ Hefei, China
}

\begin{abstract}
A novel compact wideband circularly-polarized (CP) helix antenna is presented in this paper. Unlike conventional helical geometry, our design adopts a tapered metal strip which is rolled into a conical shape and is simply fed by attaching to a $50 \Omega$ coaxial cable. All the configuration parameters are optimized by using modified multiobjective evolutionary algorithm based on decomposition (MOEA/D) for broad operation bandwidth. The proposed helix antenna provides a $-10 \mathrm{~dB}$ impedance bandwidth of more than $81 \%$ from $2.1 \mathrm{GHz}$ to above $5 \mathrm{GHz}$, a $3-\mathrm{dB}$ axialratio bandwidth of $58 \%(2.4 \mathrm{GHz} 4.36 \mathrm{GHz})$, and a $8 \mathrm{dBi}$ axial gain bandwidth of $72.5 \%(2.18 \mathrm{GHz} 4.66 \mathrm{GHz})$, which leads to an effective CP operation bandwidth of $58 \%$. The overall size of the design is $40 \mathrm{~mm} \times 40 \mathrm{~mm} \times 40 \mathrm{~mm}$, i.e., $0.45 \lambda \times 0.45 \lambda \times 0.45 \lambda$ at the centre frequency of $3.38 \mathrm{GHz}$. The compact size and wideband $\mathrm{CP}$ performance of this antenna make it promising for high speed wireless communication systems today.
\end{abstract}

Keywords- circular polarization; helical antenna; conical helix; wideband antenna

\section{INTRODUCTION}

Circularly-polarized (CP) antennas are widely employed in modern wireless systems, such as navigation, radar, satellites, and mobile systems [1]. For some applications, the CP antenna is required to operate in wide frequency band, and yet have dimensions as small as possible. Although quite a lot of wideband $\mathrm{CP}$ antennas have been reported in recent years, design of wideband compact $\mathrm{CP}$ antenna is still a challenge.

A common approach to design a $\mathrm{CP}$ antenna is using the axial-mode helical antenna [2]. For a helix antenna, it is the helix dimension, pitch angle and number of turns that characterize the radiation pattern and polarization purity. A typical cylindrical helix, generally with a big number of turns over 6, can achieve great circular polarization performance over a wide bandwidth. However the large dimension, especially the antenna height, is a significant limitation for its applications [3]. Meanwhile, the input impedance of an axialmode helix is usually between $100 \Omega$ and $200 \Omega$, which indicates an impedance transformer might be needed. A new technique for size reduction of helical antennas by replacing the wire with a tapered strip is proposed in [4]. The demonstrated helix provides a wide CP bandwidth of $63 \%$ at the antenna height of $1.659 \lambda$.

Multitudinous studies have been carried out to lower the helix height over the years, among which the low-profile curl antenna, with turns usually less than 3 , and the hemispherical helical antenna, with turns usually between 4 to 7 , are two

\author{
G. Wang \\ Key Laboratory of Electromagnetic Space Information, \\ Chinese Academy of Sciences \\ Hefei, China
}

typical structures [5, 6]. In [5], the proposed curl antenna delivers a 3-dB axial-ratio (AR) bandwidth of more than $8.6 \%$ with a small antenna height of about $0.28 \lambda$ at $12.225 \mathrm{GHz}$. Paper [6] introduces a compact ultra-wideband hemispherical helical design with dimensions of $0.47 \lambda \times 0.47 \lambda \times 0.28 \lambda$, which provides a $3-\mathrm{dB}$ AR bandwidth of $24 \%$ at the centre frequency of $3.35 \mathrm{GHz}$.

Conical log spiral antenna (CLSA), usually with two tapered arms, is also a popular axial-mode helical structure [7]. With proper feeding network, wideband even ultra-wideband CP performance can be desired. However, CLSA is a balanced system, which indicates a broadband feed balun (balanced to unbalanced transformer) to realize impedance transformation is inevitable and vital. Meanwhile, the antenna height usually cannot be significantly reduced if wideband performance is required. Recently a minimized conical spiral antenna, with an operating bandwidth of more than $60 \%$, has been reported at the height of about one wavelength at the centre frequency [8].

In this paper, a novel compact wideband helix is proposed, which is designed to have a tapered copper strip rolled into a conical shape for bandwidth enhancement and size reduction. Unlike conventional helix antennas, our design can conveniently realize impedance matching between the loaded conical helix and the feeding coaxial cable by adjusting the helix pitch and the strip width. By using modified multiobjective evolutionary algorithm based on decomposition (MOEA/D) optimization technique [9], the demonstrated design delivers a CP operation bandwidth of $58 \%$ $(2.4 \mathrm{GHz} 4.36 \mathrm{GHz})$ with an axial gain over $8 \mathrm{dBi}$, and has a compact size of $0.45 \lambda \times 0.45 \lambda \times 0.45 \lambda$ at $3.38 \mathrm{GHz}$.

\section{ANTENNA CONFIGURATION}

The geometry of the proposed compact wideband $\mathrm{CP}$ antenna is illustrated in fig.1. The conical helix is made out of a tapered copper strip with a thickness of $0.8 \mathrm{~mm}$ for fabrication convenience. And it is simply fed by attaching to a $50 \Omega$ coaxial cable through a hole on a PEC ground plane, as shown in fig. 1(a).

The dimensions of the antenna are shown in fig. 1(b) and fig. 1(c). The metal helical strip, with a thickness of $t$, stands above the ground plane at height $h$, and connects to the inner conductor of a $50 \Omega$ coaxial cable. The conical structure has an initial inner radius of $r_{0}$, a pitch of $d$, a half cone angle of $\theta_{0}=\arctan \left(\frac{a}{d}\right)$, and a number of turns of $N$. It has been 
proved that a gradient width of the helical strip, relative to a certain one, can weaken the current reflection along the strip and lead to some improvement of the CP operating bandwidth without changing the radiation too much. Thus a tapered strip width varying uniformly from $w_{0}$ to $w_{l}$ has been adopted in the demonstrated design.
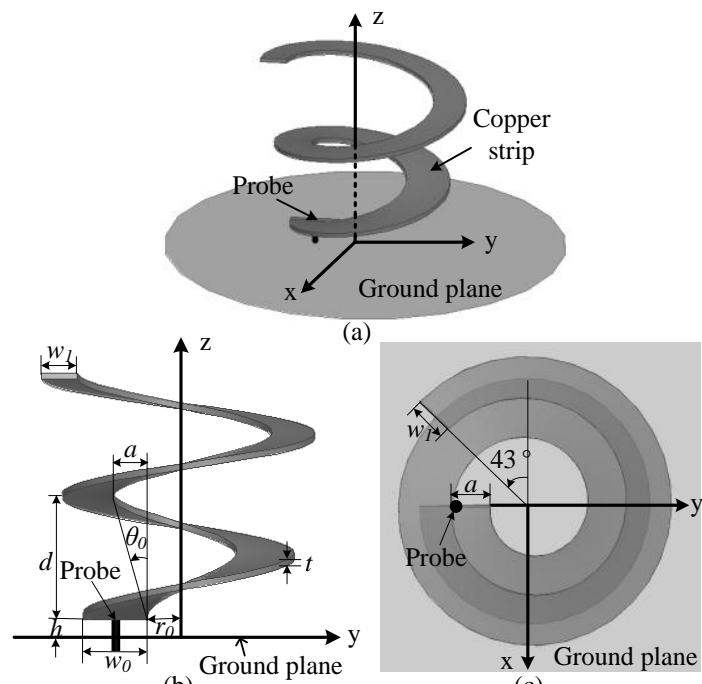

(b)

(c)

FIGURE I. CONFIGURATION OF THE PROPOSED CP ANTENNA. (A) 3-D VIEW OF THE ANTENNA, (B) FRONT VIEW OF THE ANTENNA, (C) TOP VIEW OF THE ANTENNA.

\section{DESIGN AND PERFORMANCE}

For demonstration, the antenna will be designed to cover operating frequencies from $2.4 \mathrm{GHz}$ to $4.4 \mathrm{GHz}$, with an axial radiation $\mathrm{CP}$ bandwidth of almost $59 \%$ at the centre frequency of $3.4 \mathrm{GHz}$. The overall dimensions of this antenna are restricted within $40 \mathrm{~mm} \times 40 \mathrm{~mm} \times 40 \mathrm{~mm}$, i.e., $0.45 \lambda \times 0.45 \lambda \times 0.45 \lambda$ at $3.4 \mathrm{GHz}$.

To acquire wide impedance bandwidth, 3-dB AR bandwidth, and gain bandwidth, we may define three design objectives. MOEA/D can be applied for optimization searching because of its fast convergence rate, good population diversity, and good algorithm stability [9]. Objective functions for reflection coefficient $\left(f_{1}\right), 3-\mathrm{dB} \mathrm{AR}$ $\left(f_{2}\right)$ and $8 \mathrm{dBi}$ gain $\left(f_{3}\right)$ in the axial direction over the desired band can be defined as:

$$
\begin{aligned}
f_{1} & =\frac{10}{\left|S_{11}(d B)\right|} \\
f_{2} & =\frac{\text { Axial Ratio }(d B)}{3} \\
f_{3} & =\frac{8}{|\operatorname{Gain}(d B i)|}
\end{aligned}
$$

where the constants, 10, 3, and 8, are employed for objective normalization.

After implementing MOEA/D-based optimization searching, parameters for one of the optimized conical helix antennas are listed in Table I, which delivers a compact structure of $40 \mathrm{~mm} \times 40 \mathrm{~mm} \times 40 \mathrm{~mm}$.
TABLE I. PARAMETERS OF THE CONICAL HELIX ANTENNA.

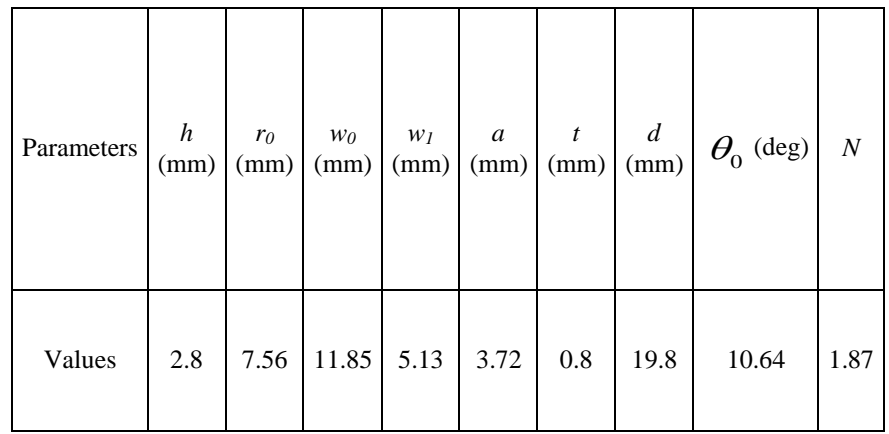

Figure 2 depicts the simulated reflection coefficient of the designed CP antenna, where a -10dB impedance bandwidth of more than $81 \%$ from $2.1 \mathrm{GHz}$ to above $5 \mathrm{GHz}$ can be observed. The simulated AR and gain along the $+z$ direction $\left(\varphi=0^{\circ}, \theta=0^{\circ}\right)$ is displayed in figure 3 , where a $3-\mathrm{dB}$ axial-ratio bandwidth of $58 \%$ from $2.4 \mathrm{GHz}$ to $4.36 \mathrm{GHz}$ and a $8 \mathrm{dBi}$ axial gain bandwidth of $72.5 \%$ from $2.18 \mathrm{GHz}$ to $4.66 \mathrm{GHz}$ can be achieved. Thus the design delivers an effective CP operation bandwidth of $58 \%$, which is much wider than the previously reported low profile helical antennas at the sacrifice of an acceptable height enlargement. The helix provides a $\mathrm{CP}$ performance almost equal to a regular axial-mode cylindrical helix, but has a relatively small size of $0.45 \lambda \times 0.45 \lambda \times 0.45 \lambda$.

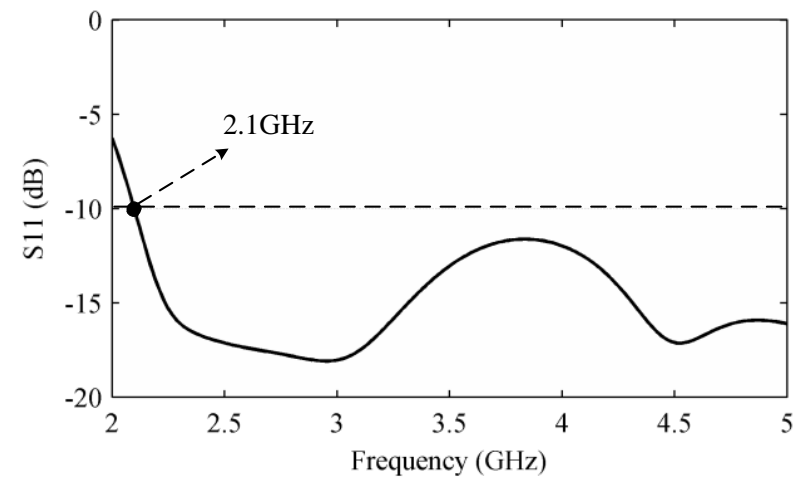

FIGURE II. SIMULATED REFLECTION COEFFICIENT OF THE PROPOSED ANTENNA.

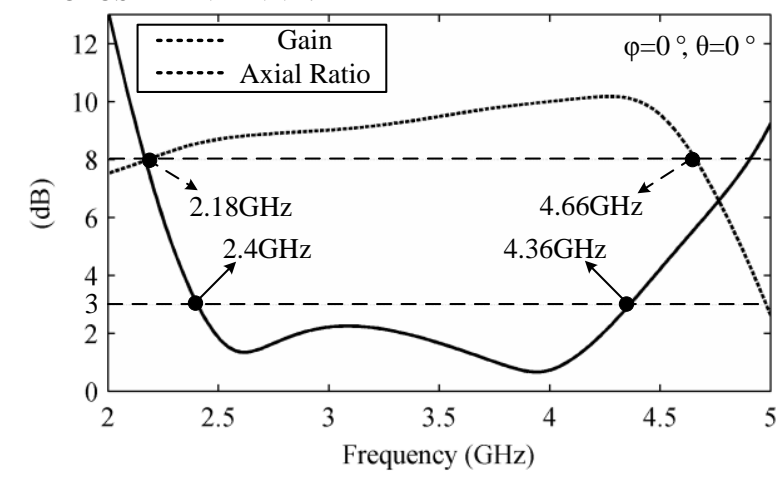

FIGURE III. SIMULATED AXIAL RATIO AND GAIN OF THE PROPOSED ANTENNA.

The impedance of the antenna at the input port is shown in fig. 4. It can be indicated that the impedance matching between the loaded conical helix and the feeding coaxial cable is roughly realized over the $\mathrm{CP}$ operation bandwidth. 


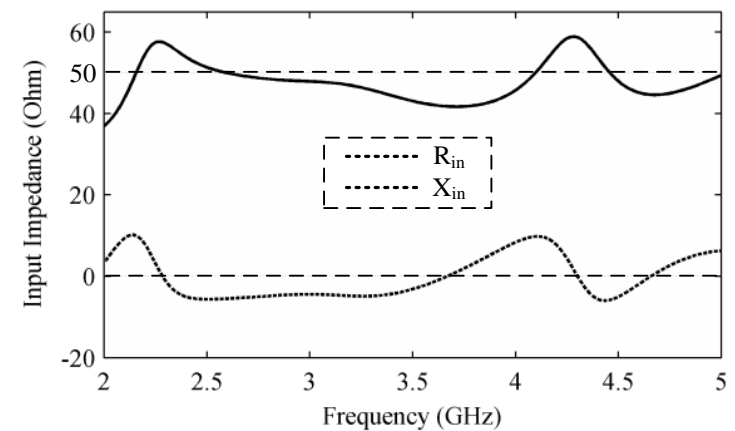

FIGURE IV. SIMULATED INPUT IMPEDANCE OF THE PROPOSED ANTENNA.

\section{FURTHER DISCUSSION}

The normalized radiation patterns of the proposed wideband conical helix at six typical frequencies of $1.5 \mathrm{GHz}$, $2.4 \mathrm{GHz}, 3.1 \mathrm{GHz}, 3.8 \mathrm{GHz}, 4.4 \mathrm{GHz}$ and $4.8 \mathrm{GHz}$ are depicted in fig. 5. From fig. 5, we can find that the half-power beamwidth of the main lobe in the $\mathrm{X}-\mathrm{z}$ plane is reduced from $80^{\circ}$ to $46^{\circ}$ as the operating frequency increases from $2.4 \mathrm{GHz}$ to $4.4 \mathrm{GHz}$.

The operation mode of helix antenna may give a clue to the change of the half-power beam-width and the gain bandwidth. As is well-known, the radiation pattern of a regular helix is closely related to the ratio between the helix diameter $D$ and the operating wavelength $\lambda$. Generally, a helical antenna presents a broadside pattern when $D / \lambda<0.18$, an axial radiation pattern (axial mode) when $D / \lambda$ is between 0.25 and 0.46 , and a conical pattern when $D / \lambda$ further increases.
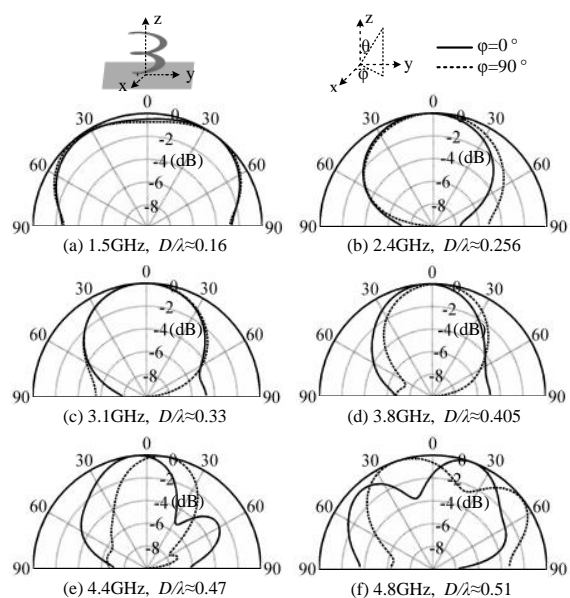

FIGURE V. NORMALIZED RADIATION PATTERNS OF THE
CONICAL HELIX AT BOTH X-Z PLANE AND Y-Z PLANE AT: (A)

$\begin{array}{llll}1.5 \mathrm{GHZ}, D / \lambda \approx 0.16 & \text { (B) } 2.4 \mathrm{GHZ}, D / \lambda \approx 0.256 & \text { (C) } 3.1 \mathrm{GHZ} \text {, }\end{array}$
$D / \lambda \approx 0.33$
(D) $3.8 \mathrm{GHZ}, \quad D / \lambda \approx 0.405$
(E) 4.4GHZ,
$D / \lambda \approx 0.47$
(D) $4.8 \mathrm{GHZ}, D / \lambda \approx 0.51$

As shown in fig.5, the equivalent normalized diameter $D / \lambda$ of the conical helix changes from 0.16 to 0.51 when the operating frequency increases from $1.5 \mathrm{GHz}$ to $4.8 \mathrm{GHz}$. It can be clearly observed that the radiation rules for a regular helix might still be suitable to some extent for a conical helix. Fortunately, the mode transformation does not occur in the $\mathrm{CP}$ operation bandwidth. Otherwise the beam pattern shall be the forth design objective for the optimization searching.

Therefore, the operation mode of a helical antenna could be another restriction factor for wideband $\mathrm{CP}$ design. The axial radiation pattern of a single-arm helix may be kept in a relative bandwidth of about $60 \%$.

It should be remarked that the radiation patterns of the designed antenna in $\mathrm{x}-\mathrm{z}$ plane and $\mathrm{y}-\mathrm{z}$ plane in fig. 5 are slightly different, which is possibly due to the small rotating turn of $N<2$.

\section{CONCLUSION}

The characteristics of a conical helix with tapered copper strip are studied in this paper. By properly adjusting the helix parameters, the conical helix which is simple fed by using a $50 \Omega$ coaxial cable, can conveniently realize impedance matching and achieve broadband CP performance. The design is demonstrated by a miniaturized wideband $\mathrm{CP}$ antenna for operating frequencies from $2.4 \mathrm{GHz}$ to $4.36 \mathrm{GHz}$ by using MOEA/D-based optimization technique which may yield the operating bandwidth as broad as possible in a single run. After optimization, the proposed antenna provides a wide $\mathrm{CP}$ bandwidth of $58 \%$, an axial gain above $8 \mathrm{dBi}$ and a relatively compact size of $40 \mathrm{~mm} \times 40 \mathrm{~mm} \times 40 \mathrm{~mm}$, i.e., $0.45 \lambda \times 0.45 \lambda \times$ $0.45 \lambda$ at the centre frequency of $3.38 \mathrm{GHz}$.

\section{ACKNOWLEDGEMENT}

This work was supported in part by National Natural Science Foundation of China under Grant 61272471.

\section{REFERENCES}

[1] S. Gao, Q. Luo \& F.G. Zhu, Circularly polarized antennas, Wiley-IEEE Press, 2014.

[2] Wheeler, H.A., A helical antenna for circular polarization, Proceedings of the IRE, vol. 35, no. 12, pp. 1484-1488, 1947

[3] Nakano, H., Samada, Y. \& Yamauchi, J., Axial mode helical antennas, IEEE Transactions on Antennas and Propagation, vol. 34, no. 9, pp. 1143-1148, 1986.

[4] Alsawaha, H. \& Safaai-Jazi, A., A new technique for bandwidth improvement and size reduction of helical antennas, Microwave and Optical Technology Letters, vol. 53, no. 12, pp. 2990-2994, 2011.

[5] Nakano, H., Kirita, S., Mizobe, N. \& Yamauchi, J., External-excitation curl antenna, IEEE Transactions on Antennas and Propagation, vol. 59, no. 11 , pp. 3969-3977, 2011

[6] Alsawaha, H.W. \& Safaai-Jazi, A., Ultrawideband hemispherical helical antennas, IEEE Transactions on Antennas and Propagation, vol. 58, no. 10, pp. 3175-3181, 2010.

[7] Dyson, J., The characteristics and design of the conical log-spiral antenna, IEEE Transactions on Antennas and Propagation, vol. 13, no. 4 pp. 488-499, 1965.

[8] T. Wei \& T. Xiong, Minimized conical spiral antenna for GNSS, 2013 IEEE International Conference on Signal Processing, Communication and Computing (ICSPCC), pp. 1-4, 2013.

[9] D.W. Ding \& G. Wang, Modified multiobjective evolutionary algorithm based on decomposition for antenna design, IEEE Transactions on Antennas and Propagation, vol. 61, no. 10, pp. 5301-5307, 2013. 